\title{
Prediction of the environmental fate and aquatic ecological impact of nitrobenzene in the Songhua River using the modified AQUATOX model
}

\author{
LEI Bingli, HUANG Shengbiao, QIAO Min, LI Tianyun, WANG Zijian*
}

\author{
State Key Laboratory of Environmental Aquatic Chemistry, Research Center for Eco-Environmental Sciences, Chinese Academy of Sciences, \\ Beijing 100085, China. E-mail: leibingli@126.com
}

Received 25 February 2008; revised 10 April 2008; accepted 30 April 2008

\begin{abstract}
An accidental discharge of nitrobenzene happened in November 2005 in the Songhua River, China. The AQUATOX model was modified and adapted to simulate the time-dependent nitrobenzene distribution in this multimedia aquatic system and its potential ecological impacts. Nitrobenzene concentrations in flowing water, sediment, and biota were predicted. Based on the initial concentrations of nitrobenzene observed in the field during the accidental discharge, that is, $0.167-1.47 \mathrm{mg} / \mathrm{L}$ at different river segments, the predicted water concentrations of nitrobenzene would be lower than 0.02 and $0.002 \mathrm{mg} / \mathrm{L}$ after twenty days and one month, respectively. Both model prediction and field observation were in good agreement. The predicted nitrobenzene concentrations in sediments and aquatic organisms would be lower than 0.025 and $0.002 \mathrm{mg} / \mathrm{kg}$, respectively, after two months. Among the environmental factors affecting nitrobenzene concentrations in water, inflow water dilution, water temperature, and initial concentration were the most important, by sensitivity analysis. Comparing the perturbed simulation and control simulation, the biomass changes for diatoms and mussel were significantly affected, whereas, no influence on other organisms could be predicted. Therefore the results indicated that nitrobenzene pollution in the Songhua River should have a limited impact on the benthos community.
\end{abstract}

Key words: nitrobenzene; environmental fate; ecological impact; the Songhua River; AQUATOX model

\section{Introduction}

Aquatic environment, as a significant and constituent part of the whole environment system, would receive a majority of pollutants. Hazardous substances released into the aquatic environment are transported and distributed in complex aquatic environmental components. Effective environmental management practices for pollution accidents are dependent on the clear understanding of the environmental fate and ecological risk of chemicals. The conventional methods and technologies for assessing the environmental fate and ecological risk of chemicals are mainly dependent on chemical analysis and biological toxicity tests, such as, instrumental detection, singlespecies toxicity tests, multiple-species toxicity tests, and mesocosm tests (Smith and Cairns, 1993; Kennedy et al., 1995). Conventional methods have their inherent virtues such as precision and credibility, however, performing a large number of these experiments may be inappropriate, because these tests are laborious, expensive, and timeconsuming (Naito et al., 2002). In contrast to the high cost for multimedia monitoring and toxicity tests, and the need for rapid forecasting analysis, a comprehensive aquatic

\footnotetext{
* Corresponding author. E-mail: wangzj@rcees.ac.cn.
}

ecological system model would be cost-effective, fast, and a suitable evaluation tool (He et al., 2001; Naito et al., 2003). An ecological model, which can be defined as a simplified representation of a specific ecological system, may be the only option for assessing chemical effects under circumstances where field experiments cannot be conducted (Ang et al., 2001). Some reviews concerning the use of ecological models in ecological risk assessment have been published (Bartell et al., 1999; Ray et al., 2001; Kumblad et al., 2003; Chow et al., 2005; Larocque et al., 2006). Among these models, AQUATOX, developed by Park et al. (2008), is one of the relatively few comprehensive models that have been designed specifically for environmental behaviors and the ecological impact assessment of pollutants.

In November 2005, a Chinese petrochemical plant exploded, and about $100 \mathrm{t}$ of chemicals were released into the Songhua River, and the main component was nitrobenzene. Nitrobenzene is an industrial chemical and used mainly as an intermediate to produce aniline and aniline-derived products, and also used to produce lubricating oils such as those used in motors and machinery. As a toxic and suspected carcinogenic compound, nitrobenzene released into the environment poses a great threat to the ecosystem and human health. Even at low concentrations it may present 
high risks to the environment because of its stability (Bhatkhande et al., 2003). Hence, it is necessary to quickly assess the environmental fate and aquatic ecological risk of the nitrobenzene released into the Songhua River by using a simple and effective evaluation tool for environment management.

In this study, to assess the environmental fate and the aquatic ecological impact of nitrobenzene released into the Songhua River after the accidental release of nitrobenzene, a comprehensive aquatic ecological system model AQUATOX was applied by slightly modifying the food web structures and model parameters according to the real environmental characteristics of the Songhua River basin. By applying this model, the authors hope to supply a simple method to monitor activities and identify key processes with regard to the environmental fate and ecological impact of such toxicants, after emergency pollution accidents.

\section{Methodology}

\subsection{Study area}

The Songhua River is located in northeast of China and is the largest tributary of the Heilongjiang River. The river is divided into four linked segments for simulation, to express the spatial resolution and environmental characteristics of the river (Fig.1). Segment 1, from the 10th line where the accident discharge happened to Sanchahe, is located in the second Songhua River, which is one of the headwaters of the Songhua River. It receives inflowing water from the Fengman reservoir upstream, as well as its two tributaries, Yitong River and Yinma River. Segment 2 is from Sanchahe to Harbin and is the upper part of the trunk of the Songhua River. It receives inflowing water from the Nenjiang River (another headwater of the Songhua River) and Lalin River. Segment 3 is from Harbin to Jiamushi and is in the middle part of the trunk of the Songhua River and five other main tributaries are located in this segment. Segment 4 is from Jiamushi to Tongjiang and is the northernmost part of the Songhua River, where there are no significant tributaries.

\subsection{Model}

The model used in this study is AQUATOX, which is a comprehensive aquatic ecosystem model predicting the environmental fate and effects of conventional pollutants,

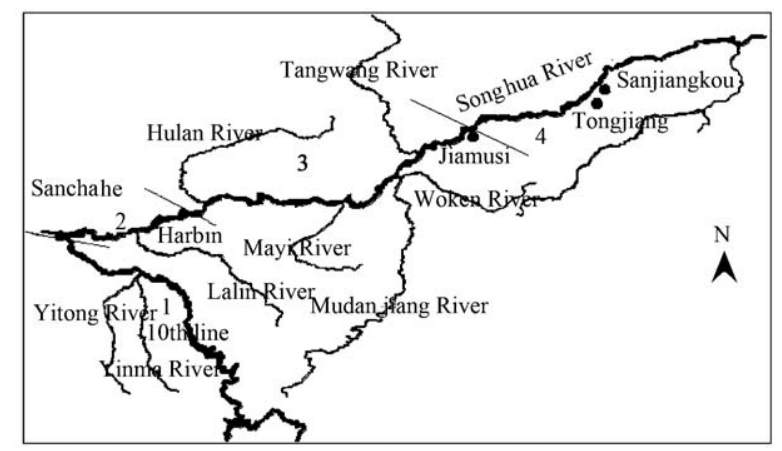

Fig. 1 Four-segment diagram of the Songhua River. such as nutrients and toxic chemicals in aquatic ecosystems.

The chemical fate portion of the AQUATOX predicts the partitioning of a chemical into water, sediment, particulate, and biota. Microbial degradation, biotransformation, photolysis, hydrolysis, and volatilization are also modeled implicitly in the AQUATOX. The effects portion of the model includes a direct toxic-effect that is used to extrapolate the potential effects of chemicals on the biomass production in an aquatic ecosystem from acute and chronic toxicity data $\left(\mathrm{LC}_{50}\right.$ or $\left.\mathrm{EC}_{50}\right)$ of single-species to the various organisms modeled, indirect effects such as an increase in detritus and recycling of nutrients from organisms that have been killed, and dissolved oxygen sag because of increased decomposition. The AQUATOX represents the aquatic ecosystem by simulating time-dependent concentrations of organisms, nutrients, and chemicals in a unit volume of water. The fundamental equation used in the AQUATOX to simulate time-dependent nitrobenzene concentrations in water is described in Eq.(1) (USEPA, 2004b).

$$
\begin{aligned}
\frac{d \mathrm{C}_{\mathrm{W}}}{d t}= & R_{\mathrm{L}}+\sum{ }_{\mathrm{LD}}\left(R_{\mathrm{Dec}} \times \mathrm{PPB}_{\mathrm{LD}} \times 1 e-6\right)+ \\
& \sum R_{\mathrm{Des}}+\sum R_{\mathrm{Dep}}-\sum R_{\mathrm{Sor}}- \\
& \sum R_{\mathrm{GU}}-R_{\mathrm{MU}}-\sum R_{\mathrm{AU}}-R_{\mathrm{Hyd}} \\
& -R_{\mathrm{Pho}}-R_{\mathrm{MD}}+R_{\mathrm{Vol}}-R_{\mathrm{Dis}}+R_{\mathrm{Bio}} \pm R_{\mathrm{TD}}
\end{aligned}
$$

where, $C_{\mathrm{W}}(\mathrm{mg} / \mathrm{L})$ is the toxicant concentration in a dissolved phase, in a unit volume of water; $R_{\mathrm{L}}(\mathrm{mg} /(\mathrm{L} \cdot \mathrm{d}))$ is the loading rate of the toxicant from external sources; $R_{\text {Dec }}$ $(\mathrm{g} /(\mathrm{L} \cdot \mathrm{d}))$ is the rate of decomposition of a given detritus; $\mathrm{PPB}_{\mathrm{LD}}(\mathrm{mg} / \mathrm{kg})$ is the concentration of a chemical in labile detrious $i ; R_{\text {Des }}(\mathrm{mg} /(\mathrm{L} \cdot \mathrm{d}))$ is the desorption rate of the toxicant from a given compartment; $R_{\text {Dep }}(\mathrm{mg} /(\mathrm{L} \cdot \mathrm{d}))$ is the elimination rate of the toxicant because of clearance; $R_{\text {Sor }}(\mathrm{mg} /(\mathrm{L} \cdot \mathrm{d}))$ is the sorption rate of the toxicant to a given compartment; $R_{\mathrm{GU}}(\mathrm{mg} /(\mathrm{L} \cdot \mathrm{d}))$ is the absorption rate of the toxicant by gills; $R_{\mathrm{MU}}(\mathrm{mg} /(\mathrm{L} \cdot \mathrm{d}))$ is the sorption rate of the toxicant by macrophytes; $R_{\mathrm{AU}}(\mathrm{mg} /(\mathrm{L} \cdot \mathrm{d}))$ is the sorption rate of the toxicant by algae; $R_{\mathrm{Hyd}}(\mathrm{mg} /(\mathrm{L} \cdot \mathrm{d}))$ is the hydrolysis rate of the toxicant; $R_{\mathrm{Pho}}(\mathrm{mg} /(\mathrm{L} \cdot \mathrm{d}))$ is the direct photolysis rate of the toxicant; $R_{\mathrm{MD}}$ is the microbial degradation rate of the toxicant $(\mathrm{mg} /(\mathrm{L} \cdot \mathrm{d}))$; $R_{\mathrm{Vol}}$ is the volatilization rate of the toxicant $(\mathrm{mg} /(\mathrm{L} \cdot \mathrm{d}))$; $R_{\text {Dis }}(\mathrm{mg} /(\mathrm{L} \cdot \mathrm{d}))$ is the discharge downstream rate of the toxicant; $R_{\text {Bio }}(\mathrm{mg} /(\mathrm{L} \cdot \mathrm{d}))$ is the biotransformation rate to or from a given organic chemical in a given detrital compartment because of microbial decomposition; $R_{\mathrm{TD}}$ $(\mathrm{mg} /(\mathrm{L} \cdot \mathrm{d}))$ is the depth-averaged turbulent diffusion rate between epilimnion and hypolimnion.

To reflect the characteristics of the Songhua River, the original version of AQUATOX was modified for the foodweb structure and the environmental conditions. Fig.2 shows the conceptual model and the structure of the food web in the Songhua River. In this diagram, each box or circle represents one model population or a state variable. Arrows represent the mutual relations between populations or state variables. 


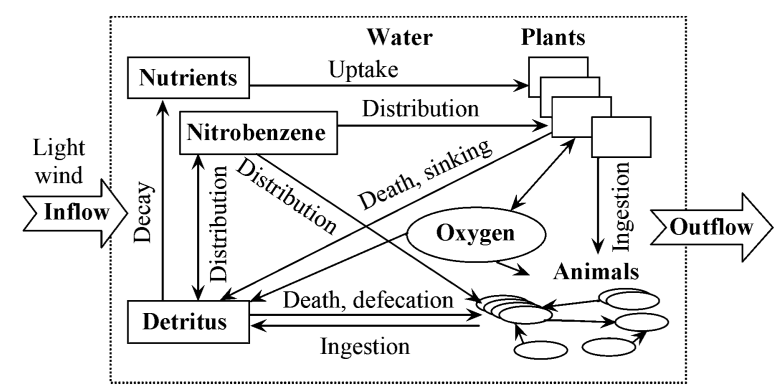

Fig. 2 Conceptual model depiction and structure of web food for the Songhua River aquatic ecosystem in this study.

\subsection{Parameterization}

\subsubsection{Biomass and physiological parameters of organ- isms}

The modeled biological species are typically found in the Songhua River aquatic ecosystem, consisting of three phytoplankton populations, one macrophyte, two zooplankton populations, one benthic insect population,

Table 1 List of species and physiological parameters used for producer populations

\begin{tabular}{|c|c|c|c|c|}
\hline \multicolumn{2}{|c|}{ Population } & \multicolumn{2}{|c|}{ Phytoplankton } & \multirow{2}{*}{$\frac{\text { Macrophyte }}{\text { Myriophyllum }}$} \\
\hline Species & Diatoms & Greens & Blue-greens & \\
\hline$B_{0}$ & 1.96 & 0.38 & 0.49 & 0.01 \\
\hline$L_{\mathrm{s}}(\mathrm{Ly} / \mathrm{d})$ & 150 & 100 & 300 & 235 \\
\hline$K_{\mathrm{p}}(\mathrm{mg} / \mathrm{L})$ & 0.002 & 0.007 & 0.006 & 0 \\
\hline$K_{\mathrm{N}}(\mathrm{mg} / \mathrm{L})$ & 0.007 & 0.800 & 0.560 & 0 \\
\hline$T_{0}\left({ }^{\circ} \mathrm{C}\right)$ & 20 & 25 & 30 & 35 \\
\hline$P_{\mathrm{m}}\left(\mathrm{d}^{-1}\right)$ & 3.10 & 1.80 & 3.90 & 1.20 \\
\hline$R_{\text {resp }}\left(\mathrm{d}^{-1}\right)$ & 0.026 & 0.030 & 0.020 & 0.024 \\
\hline$M_{\mathrm{c}}\left(\mathrm{d}^{-1}\right)$ & 0.030 & 0.030 & 0.001 & 0.001 \\
\hline$L_{\mathrm{e}}\left(\mathrm{m}^{-1}\right)$ & 0.140 & 0.024 & 0.100 & 0.050 \\
\hline$R_{\text {sink }}(\mathrm{m} / \mathrm{d})$ & 0.01 & 0.01 & 0.01 & - \\
\hline$W / D$ & 5 & 5 & 5 & 5 \\
\hline
\end{tabular}

$B_{0}$ : the initial biomass, $\mathrm{mg} / \mathrm{L}$ for phytoplankton and $\mathrm{mg} / \mathrm{m}^{2}$ for macrophyte; $L_{\mathrm{s}}$ : light saturation level for photosynthesis; $K_{\mathrm{p}}$ : half-saturation constant for phosphorus; $K_{\mathrm{N}}$ : half-saturation constant for nitrogen; $T_{0}$ : the optima temperature; $P_{\mathrm{m}}$ : the maximum photosynthesis rate; $R_{\text {resp }}$ : the respiration rate; $M_{\mathrm{c}}$ : the mortality coefficient; $L_{\mathrm{e}}$ : light extinction; $R_{\text {sink }}$ : the sinking rate; $W / D$ : the ratio of wet weight and dry weight. Ly: Langley, $1 \mathrm{Ly}=10 \times 4.1868 \mathrm{~kJ} / \mathrm{m}^{2}$. a single benthic invertebrate population, four omnivorous fish populations, as well as a single piscivorous fish population. The relevant physiological parameters used in the model are either from the original AQUATOX model, or from the biological and ecological literature, with professional judgment (Grimaldi and Leduc, 1973; Chambers and Kalff, 1985; Lacasse and Magnan, 1992; Tang and Peters, 1995; Bartell et al., 1999; USEPA, 2004a, 2004b, 2004c). The initial biomass of the modeled organisms was obtained from history, observed data or approximately estimated through history records (Ren, 1981; Songliao Water Conservancy Committee, 1994). The data for plant populations and animal populations are summarized in Tables 1 and 2, respectively.

\subsubsection{Characteristics of the Songhua River}

Basic hydrologic data and water quality parameters were collected from history reports of the Songhua River Hydrological Station. They have been compiled and summarized in Table 3 for the determination of model initial inputs for environmental characteristics of the river (Jilin Province Hydrology Station, 1980, 1981, 1983; Songliao Water Conservancy Committee, 1994). These parameter values were obtained directly from history hydrologic data or from computing, according to the equations relevant to the model.

\subsubsection{Modeled parameters for nitrobenzene}

Parameters for nitrobenzene included initial concentrations, physicochemical properties, and toxicity data. The maximum measured field concentrations of nitrobenzene in four segment waters $(1.47,0.581,0.258,0.167 \mathrm{mg} / \mathrm{L})$ were used in the model as the nitrobenzene initial water concentration at each segment. These concentrations were obtained from the Hydrological Station of the Songhua River. The main physicochemical properties and singlespecies toxicity data of nitrobenzene used in the model are summarized from literature and database and are listed in Tables 4 and 5, respectively. When several studies were made on one species with the same test duration, the geometric mean of $\mathrm{LC}_{50}$ or $\mathrm{EC}_{50}$ values was used.

Table 2 List of species and parameters used for consumer populations

\begin{tabular}{|c|c|c|c|c|c|c|c|c|c|}
\hline \multirow{2}{*}{$\begin{array}{l}\text { Population } \\
\text { Species }\end{array}$} & \multicolumn{2}{|c|}{ Zooplankton } & \multirow{2}{*}{$\begin{array}{l}\text { Benthic insect } \\
\text { Chironomid }\end{array}$} & \multirow{2}{*}{$\begin{array}{l}\text { Benthic invertebrate } \\
\text { Mussel }\end{array}$} & \multicolumn{4}{|c|}{ Omnivorous fish } & \multirow{2}{*}{$\frac{\text { Piscivorous fish }}{\text { Perch }}$} \\
\hline & Daphnia & Rotifer & & & Minnow & Carp & Catfish & Trout & \\
\hline$B_{0}$ & 0.29 & 1.52 & 0.09 & 1.00 & 0.20 & 0.18 & 0.06 & 0.09 & 0.01 \\
\hline$H_{\mathrm{s}}$ & 0.250 & 1.000 & 1.000 & 1.000 & 0.025 & 0.500 & 1.000 & 1.500 & 1.000 \\
\hline$C_{\mathrm{m}}(\mathrm{g} /(\mathrm{g} \cdot \mathrm{d}))$ & 1.20 & 3.40 & 3.00 & 0.48 & 0.36 & 0.05 & 0.05 & 0.01 & 0.07 \\
\hline$P_{\min }(\mathrm{mg} / \mathrm{L})$ & 0.03 & 0.06 & 0.00 & 0.00 & 0.20 & 0.50 & 0.25 & 0.25 & 0.25 \\
\hline$T_{0}\left({ }^{\circ} \mathrm{C}\right)$ & 26 & 25 & 26 & 22 & 29 & 22 & 30 & 12 & 23 \\
\hline$R_{\text {resp }}\left(\mathrm{d}^{-1}\right)$ & 0.1800 & 0.3400 & 0.0350 & 0.0058 & 0.0150 & 0.0050 & 0.0050 & 0.0015 & 0.004 \\
\hline$C_{\mathrm{c}}$ & 8.00 & 2.50 & 10.0 & 10.0 & 0.80 & 16.7 & 4.20 & 0.05 & 0.90 \\
\hline$M_{\mathrm{c}}\left(\mathrm{d}^{-1}\right)$ & 0.0020 & 0.1000 & 0.0010 & 0.0500 & 0.0100 & 0.0030 & 0.0004 & 0.0010 & 0.0018 \\
\hline$L_{\mathrm{f}}$ (wet wt.) & 0.050 & 0.030 & 0.050 & 0.050 & 0.047 & 0.100 & 0.060 & 0.080 & 0.050 \\
\hline$W / D$ & 5 & 5 & 5 & 5 & 5 & 5 & 5 & 5 & 5 \\
\hline
\end{tabular}

$B_{0}$ : the initial biomass, $\mathrm{mg} / \mathrm{L}$ for plankton and $\mathrm{mg} / \mathrm{m}^{2}$ for benthic animal and macrophyte; $H_{\mathrm{s}}$ : the half saturation feeding, $\mathrm{mg} / \mathrm{L}$ for plankton and fish, and $\mathrm{g} / \mathrm{m}^{2}$ for benthic animal; $C_{\mathrm{m}}$ : the maximum consumption rate; $P_{\min }$ : the minimum prey for feeding; $T_{0}$ : the optima temperature; $R_{\text {resp }}$ : endogenous respiration rate; $C_{\mathrm{c}}$ : carrying capacity, $\mathrm{mg} / \mathrm{L}$ for plankton and fish, and $\mathrm{g} / \mathrm{m}^{2}$ for benthic animal; $M_{\mathrm{c}}$ : the mortality coefficient; $L_{\mathrm{f}}$ : the initial lipid fraction; $W / D$ : the ratio of wet weight and dry weight. 
Table 3 Main environmental characters for the four segments of the Songhua River

\begin{tabular}{|c|c|c|c|c|c|c|c|c|c|c|}
\hline \multirow[t]{2}{*}{ Segment } & \multicolumn{10}{|c|}{ Hydrologic data and water quality parameters } \\
\hline & $\begin{array}{l}\text { Length } \\
(\mathrm{km})\end{array}$ & $\begin{array}{l}\text { Depth } \\
(\mathrm{m})\end{array}$ & $\begin{array}{l}\text { Area } \\
\left(\times 10^{8} \mathrm{~m}^{2}\right)\end{array}$ & $\begin{array}{l}\text { Volume } \\
\left(\times 10^{8} \mathrm{~m}^{3}\right)\end{array}$ & $\begin{array}{l}\text { Input } \\
\left(\times 10^{7} \mathrm{~m}^{3} / \mathrm{d}\right)\end{array}$ & $\begin{array}{l}\text { Temp. } \\
\left({ }^{\circ} \mathrm{C}\right)\end{array}$ & $\begin{array}{l}\mathrm{DO} \\
(\mathrm{mg} / \mathrm{L})\end{array}$ & $\mathrm{pH}$ & $\begin{array}{l}\mathrm{NH}_{4}{ }^{+}-\mathrm{N} \\
(\mathrm{mg} / \mathrm{L})\end{array}$ & $\begin{array}{l}\text { Dissolved-P } \\
(\mathrm{mg} / \mathrm{L})\end{array}$ \\
\hline The 10th line-Sanchahe & 300 & 4.0 & 1.0 & 2.0 & 3.0 & 5 & 7.5 & 7.3 & 0.09 & 0.03 \\
\hline Sanchahe-Harbin & 240 & 5.5 & 1.2 & 6.6 & 6.2 & 0 & 6.4 & 7.2 & 0.29 & 0.03 \\
\hline Harbin-Jiamusi & 432 & 9.0 & 3.2 & 12 & 6.4 & 0 & 7.3 & 7.3 & 0.10 & 0.03 \\
\hline Jiamushi-Tongjiang & 267 & 2.5 & 2.4 & 15 & 7.8 & 0 & 9.3 & 7.2 & 0.15 & 0.03 \\
\hline
\end{tabular}

Table 4 Main physico-chemical properties of nitrobenzene*

\begin{tabular}{|c|c|c|c|}
\hline Nitrobenzene property & Value & Nitrobenzene property & Value \\
\hline CAS registry number & $98-95-3$ & Octanol-water partition coefficient, $\log K_{\text {ow }}$ & 1.85 \\
\hline Relative molecular weight (g/mol) & 123.11 & Organic carbon partition coefficient, $K_{\mathrm{oc}}(\mathrm{L} / \mathrm{kg})$ & $36-360$ \\
\hline Solubility (mg/L) & 1,900 at $20^{\circ} \mathrm{C}$ & Microbial degradation rate constant, $K_{\mathrm{b}}\left(\mathrm{h}^{-1}\right)$ & 0.223 at $20^{\circ} \mathrm{C}$ \\
\hline Henry's low constant $\left(\left(\mathrm{Pa} \cdot \mathrm{m}^{3}\right) / \mathrm{mol}\right)$ & 2.3 at $25^{\circ} \mathrm{C}$ & Photolysis coefficient $\left(\mathrm{d}^{-1}\right)$ & 0.007 \\
\hline Boiling point $\left({ }^{\circ} \mathrm{C}\right)$ & 210.9 at $10^{5} \mathrm{~Pa}$ & Bioaccumulation factor for fish (BCF) & $10-15$ \\
\hline Vapor pressure $(\mathrm{Pa})$ & 20 at $20^{\circ} \mathrm{C}$ & & \\
\hline
\end{tabular}

* Lang et al., 1998; USEPA, 1995.

Table 5 Use of the toxicity data of nitrobenzene in the model*

\begin{tabular}{llll}
\hline Accepted species & $\begin{array}{l}\text { Test time } \\
(\mathrm{h})\end{array}$ & $\begin{array}{l}\text { Toxicity } \\
\text { endpoint }\end{array}$ & $\begin{array}{l}\text { Toxicity value } \\
(\mathrm{mg} / \mathrm{L})\end{array}$ \\
\hline Diatoms & 96 & $\mathrm{EC}_{50}$ & 10.3 \\
Green algae & 96 & $\mathrm{EC}_{50}$ & 18.0 \\
Blue algae & 192 & $\mathrm{EC}_{50}$ & 1.90 \\
Daphnia magna & 24 & $\mathrm{LC}_{50}$ & 54.4 \\
Fathead minnow & 96 & $\mathrm{LC}_{50}$ & 117 \\
Carp & 48 & $\mathrm{LC}_{50}$ & 60.0 \\
Rainbow trout & 96 & $\mathrm{LC}_{50}$ & 24.2 \\
\hline
\end{tabular}

* Pesticide Action Network, 2006.

\subsubsection{Nitrobenzene determination in sediment of the Songhua River}

To obtain field observations of nitrobenzene in the sediment of the Songhua River, nitrobenzene had been determined in the sediment of the Songhua River by GCECD (gas chromatography with electron capture detector, Agilent, USA) analysis following sample collection, ultrasonic extraction with hexane/acetone (1:1), and cleanup with Florisil. A detailed analytical procedure can be found in the EPA method 8091 (USEPA, 1996). Mean recoveries for nitrobenzene were satisfactory with $(99 \pm 7) \%$. Method detection limit (MDL) for nitrobenzene was $0.01 \mathrm{mg} / \mathrm{kg}$. On 23 December 2005, in segments 1, 2, and 4 of the Songhua River, the measured nitrobenzene concentrations in the sediment were $0.15,0.03$, and $0.02 \mathrm{mg} / \mathrm{kg}$, respectively, whereas, in segment 3 of the Songhua River, the nitrobenzene concentrations in the sediment were lower than the method detection limit $(0.01 \mathrm{mg} / \mathrm{kg})$.

\section{Results and discussion}

\subsection{Predicted nitrobenzene concentrations in water and sediment}

The simulated nitrobenzene initial concentrations in the water for four segments of the river were normalized by the maximum measured concentrations of nitrobenzene. The predicted time-dependent daily mean nitrobenzene concentrations in water in the four segments are illustrated in Fig.3. It could be seen that the nitrobenzene concentrations in the water column decreased dramatically with time and distance. Nitrobenzene concentrations in the water of segments 1, 2, 3, and 4 were lower than $0.02 \mathrm{mg} / \mathrm{L}$ in the water quality criteria, on day $11,16,15$, and 8 , respectively. After a month, nitrobenzene concentrations in the river water were lower than $0.002 \mathrm{mg} / \mathrm{L}$. Through model simulation, major factors affecting the water concentration included inflowing water dilution, photolysis, volatilization, degradation, bioaccumulation, and absorption by sediments. The predicted nitrobenzene concentrations in water were compared with the field observations from the Songhua River Hydrological Station (Fig.4). The time-dependent variations of nitrobenzene in water were quite similar, whereas, the predicted nitrobenzene concentration in the water in each segment was higher than the observed ones, at the same time. The discrepancy could be explained by the historical hydrological data of the Songhua River used in the model, which might be different from the environmental conditions during the pollution accident. Also, the measured nitrobenzene concentration was limited and only one data at each segment was available. Reliable prediction results could be obtained when more accurate parameters and field data were available.

Adsorption of nitrobenzene on sediments and particulates including nonliving organic material and associated decomposers (bacteria and fungi) were simulated, whereas, inorganic sediments including sand, silt, and clay were exclusive because of their limited adsorption capacity. The contents of organic material in the sediment of the second Songhua River were in the range of $2 \%-6 \%$ (Lang et al., 1998). An arithmetic mean of $4 \%$ for the organic material content of the sediment and particulate was used in the model to predict the adsorption processes. The time-dependent mean nitrobenzene concentration of nitrobenzene in total sediment and particulate is shown in Fig.5. Obviously, nitrobenzene concentrations in the sediments and particulates increased sharply in the initial few days and then decreased rapidly. The predicted nitrobenzene concentrations in the sediments were slightly higher than those in the particulates. In about two 

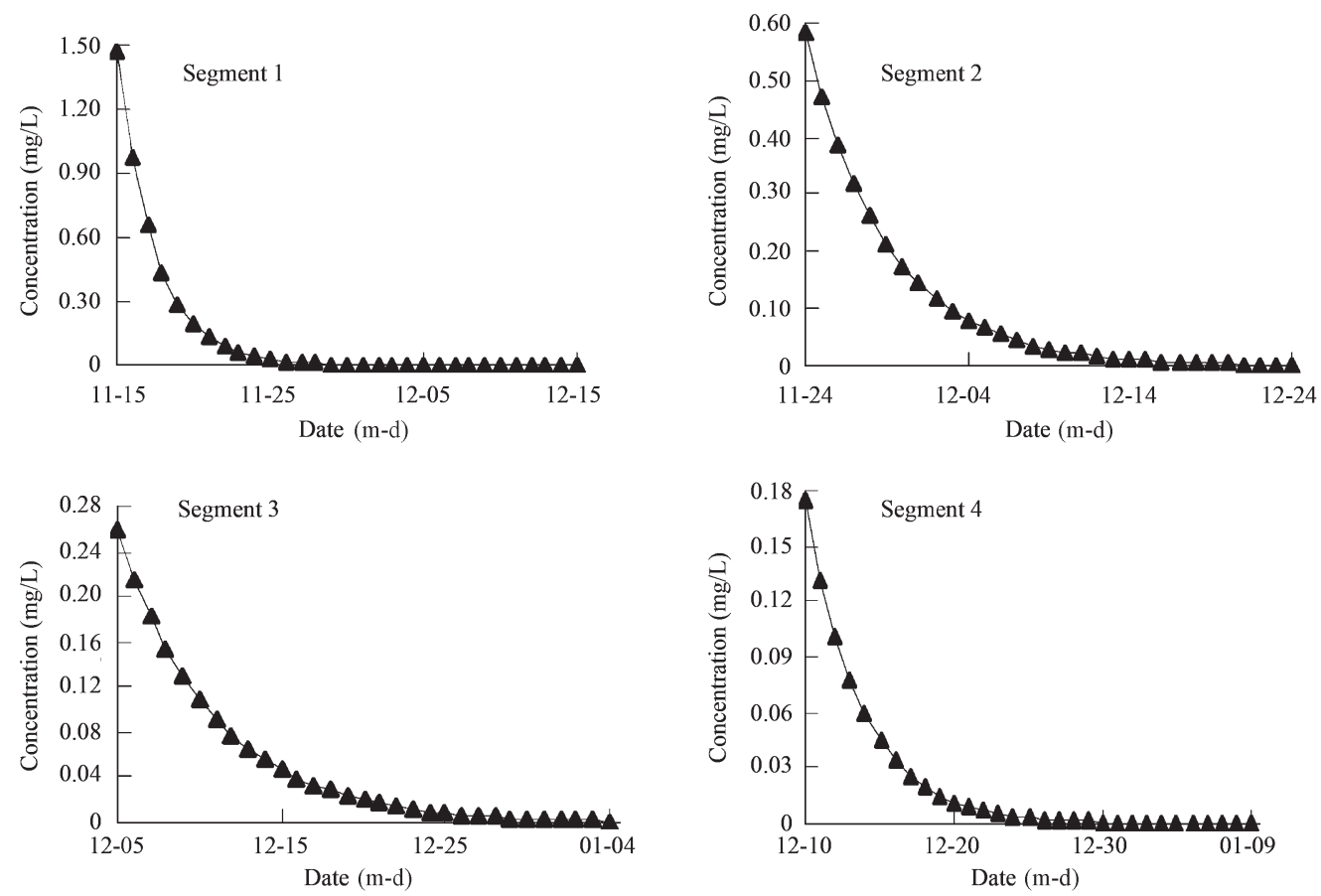

Fig. 3 An established simulation daily mean concentration change of nitrobenzene in four segment water of the Songhua River in a month
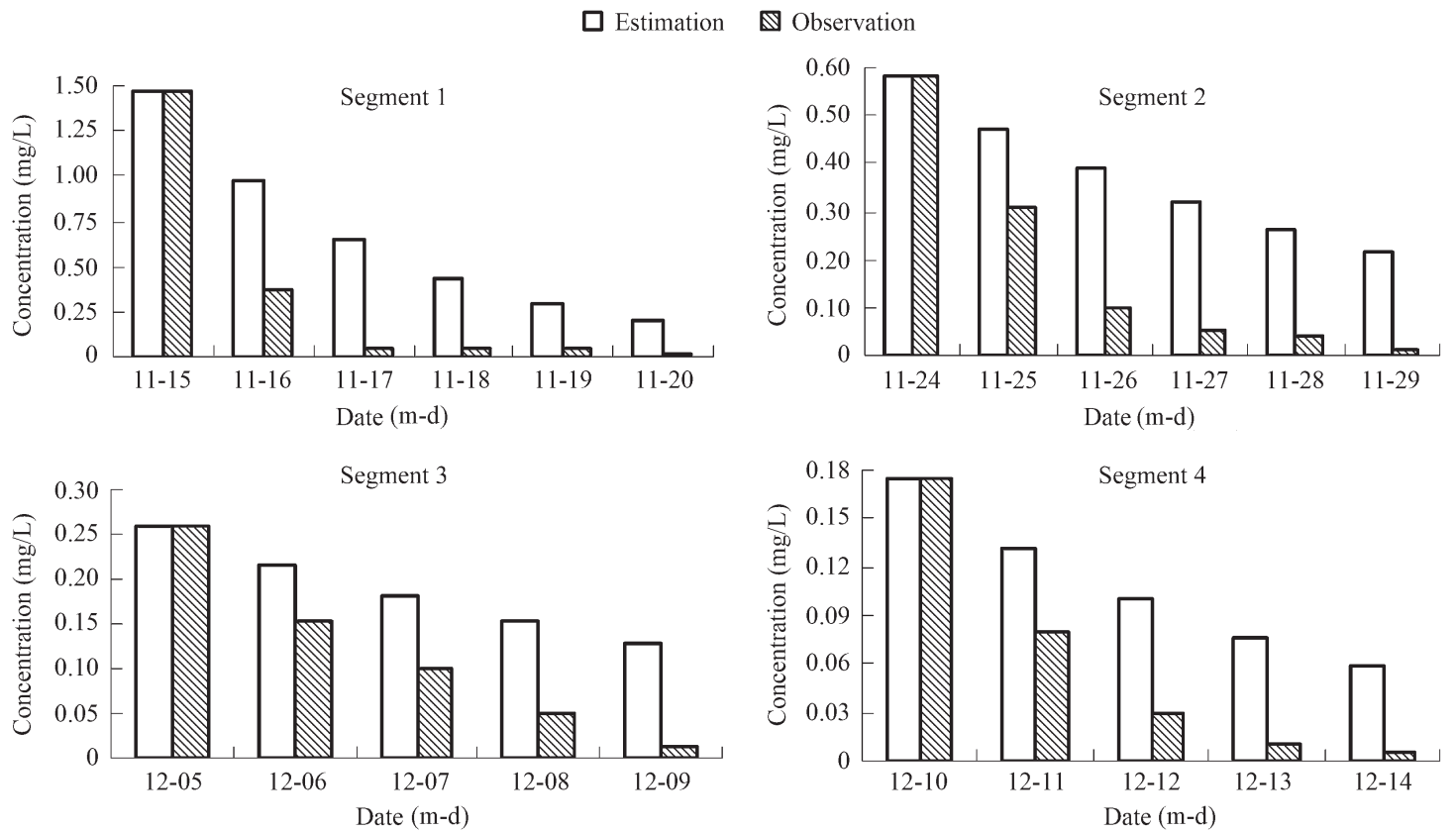

Fig. 4 Comparison of the model prediction and the observed data for the concentration change of nitrobenzene in surface water in the Songhua River.

months, the nitrobenzene residue in the sediments and particulates reached the history level ranging from 0.011 to $0.920 \mathrm{mg} / \mathrm{kg}$ (Lang et al., 1998). It had reported that nitrobenzene with low $K_{\mathrm{oc}}(36-360 \mathrm{~L} / \mathrm{kg})$ and relatively high solubility $(1,900 \mathrm{mg} / \mathrm{L})$ was not easy to be adsorbed on sediments (He et al., 2006). The predicted nitrobenzene concentrations in the sediments were compared with the monitoring data. In segment 1 , the predicted nitrobenzene mean concentration in the sediments was $0.183 \mathrm{mg} / \mathrm{kg}$ on 23 December 2005. It was consistent with the measured nitrobenzene concentration of $0.15 \mathrm{mg} / \mathrm{kg}$ in the sediment of the same segment and the same time. In segments 2 and 4 , the predicted nitrobenzene mean concentrations in the sediments were 0.169 and $0.145 \mathrm{mg} / \mathrm{kg}$, respectively, on 23 December 2005. They were slightly higher than the measured nitrobenzene concentrations $(0.03$ and 0.02 $\mathrm{mg} / \mathrm{kg}$ ) in the sediment of the same segment and the same time. For segment 3, because of lack of monitoring data, detailed comparisons could not be performed.

\subsection{Bioaccumulation}

Time-dependent daily mean concentrations of nitrobenzene in diatoms, daphnia, mussel, and carp are representatively demonstrated in Fig.6. Accumulations of 

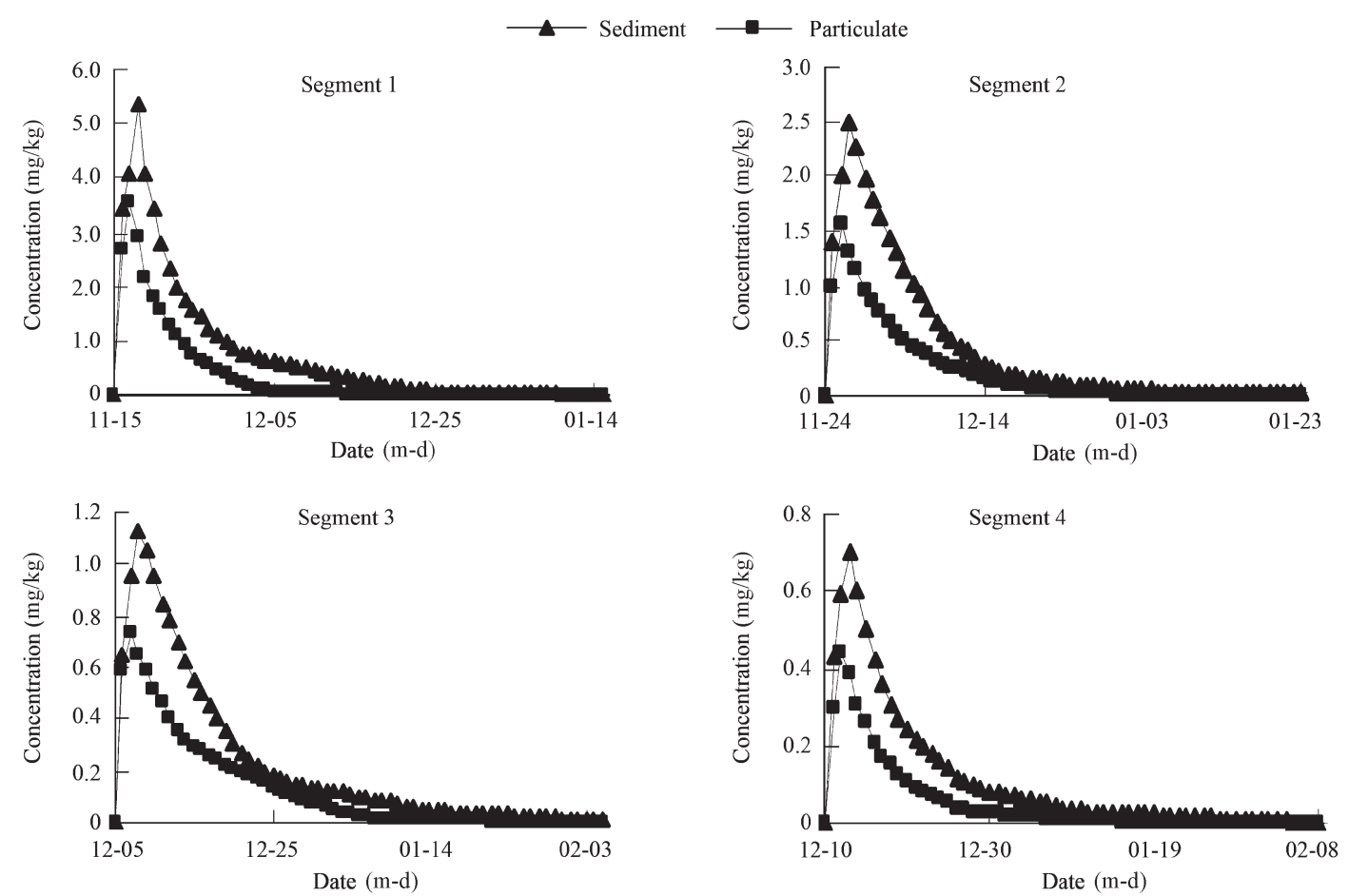

Fig. 5 An established simulation for daily mean concentration changes of nitrobenzene in the sediment and particulate in four segments of the Songhua River in two months.
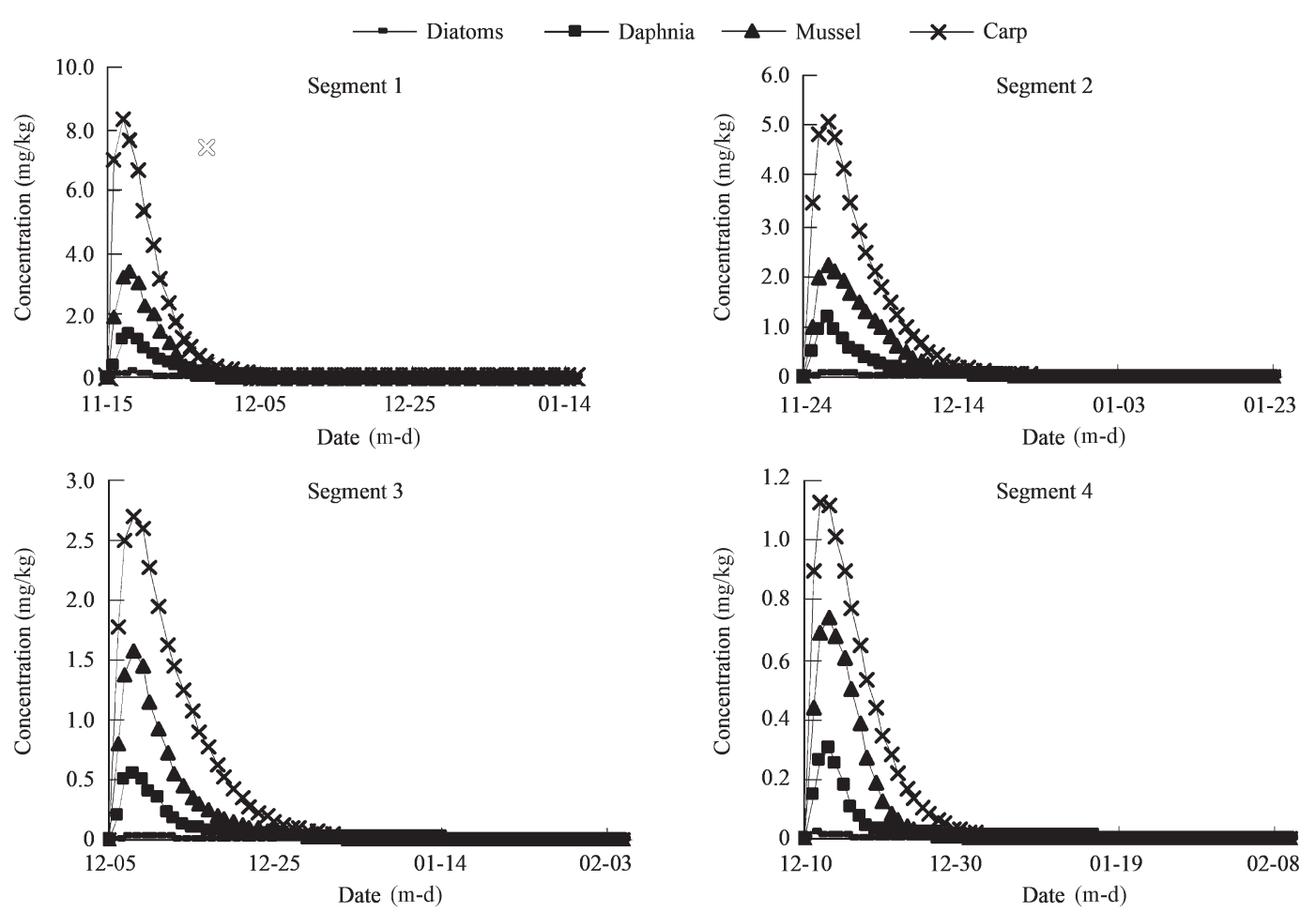

Fig. 6 An established simulation for daily mean concentration changes of nitrobenzene in different biota in four segments of the Songhua River in two months.

nitrobenzene in these four species could represent its potential accumulations in algae, zooplankton, benthic invertebrate, and fish, respectively. The results showed that nitrobenzene residues were different in different organisms, and the highest and lowest nitrobenzene concentrations were found in carp and in diatoms, respectively.
At the end of two months, nitrobenzene residues in all organisms decreased to lower than $0.002 \mathrm{mg} / \mathrm{kg}$, which could be explained by the lower biological concentration factors $(\mathrm{BCF}=10-15)$, the relatively higher solubility $(1,900 \mathrm{mg} / \mathrm{L})$ of nitrobenzene in water, and degradability in biota (Geyer et al., 1984; Deneer et al., 1987; Patil 
and Shinde, 1988). Because of lack monitoring data, comparisons between predicted and observed values of nitrobenzene concentrations in organisms could not be conducted.

\subsection{Aquatic ecological impact}

AQUATOX includes perturbed simulation and control simulation. It presents biomass change results of a simulation with perturbation and without perturbation, respectively. However, the biomass difference graph of perturbed simulation and control simulation is more informative, as it plots the biomass percentage difference in the perturbed and the control values for different organisms. It is an excellent way to describe the direct and indirect effects of perturbation. To simplify the presentation, the authors have only reported the comparative analyses of patterns of biomass change with nitrobenzene simulation and without nitrobenzene simulation. Molded biomass percentage differences for different organisms in the Songhua River are demonstrated in Fig.7. For phytoplankton population and benthic invertebrate population, such as diatoms and mussel, which are relatively more sensitive to the nitrobenzene, they show a relatively large biomass percentage difference under nitrobenzene exposure. In segment 1 , the maximal biomass percentage differences for diatoms and mussel are more than $20 \%$ and $60 \%$, respectively, because of relatively high water concentration of nitrobenzene, which could mainly be the result of direct toxic effects. In the other three segments of the river, with a decline in the nitrobenzene initial water concentration, the biomass percentage differences for diatoms and mussel are also declined. In segment 4 , the biomass percentage differences for diatoms and mussel are lower than $20 \%$ and $30 \%$. Other organisms such as daphnia and carp do not show obvious biomass percentage difference with nitrobenzene simulation and without nitrobenzene simulation because of low sensitivity to nitrobenzene. Therefore the results indicate that nitrobenzene pollution in the Songhua River should have limited impact on the benthos community.

\subsection{Sensitivity analysis}

To estimate the possible variability or uncertainty in each item of input data and deduce the probable error in the output, the highest sensitivity input parameters should be identified. AQUATOX provides probabilistic modeling approaches by allowing the user to specify the types of distributions and key statistics for any and all input variables. Efficient sampling from the distributions is obtained by using the Latin hypercube sampling method (LHS) (USEPA, 2004b). The sensitivity $\left(S_{I i}^{2}\right)$ can be calculated as the ratio between the standard deviations of output and input:

$S_{I i}^{2}=\frac{\sigma_{0, I i}^{2}}{\sigma_{I i}^{2}}$

where, $S_{I i}^{2}$ is the sensitivity of output to changes in input, $\sigma_{0, I i}^{2}$ is the variance of output contributed by the uncertainty in $i$ th input parameter and $\sigma_{I i}^{2}$ is the variance in the lognormal distribution of the $i$ th input parameter.

In this study, for simple representation, the sensitivity of some input parameters to the nitrobenzene concentration change in the water column was analyzed, to understand
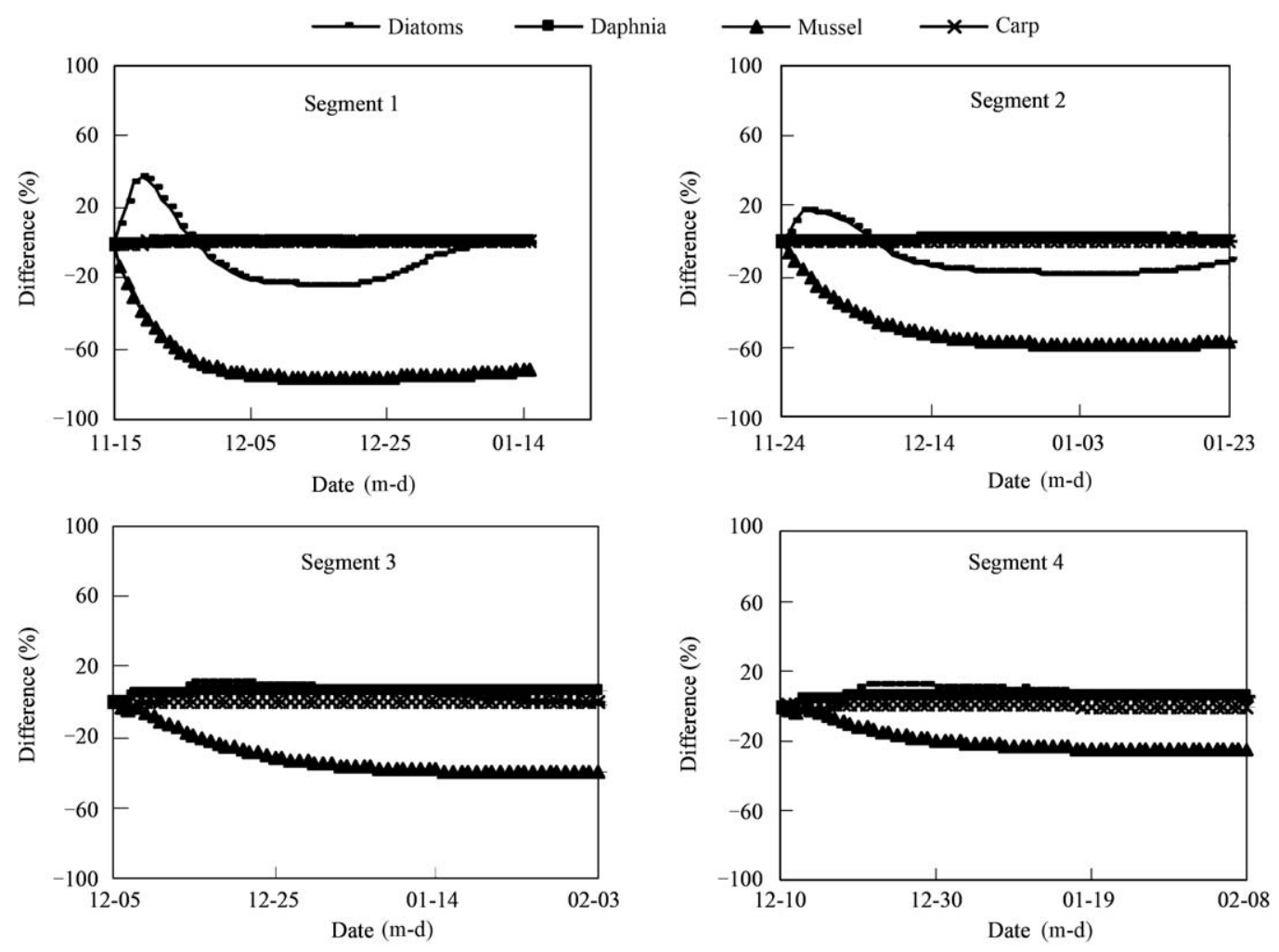

Fig. 7 Biomass difference graph with nitrobenzene simulation and without nitrobenzene simulation. 
which input parameters were relatively important to the output, by characterizing the degree of monotonic relationship between the model prediction and uncertain inputs. The results indicated that the initial concentration, inflow water volumes from the upstream or tributary, water temperature, light intensity, and the degradation rate and photolysis rate in water, were the top six most sensitive input parameters for predicting nitrobenzene concentrations in water. Among all the factors, the initial water concentration of nitrobenzene and input water volumes had a strong influence on the uncertainty in calculated nitrobenzene concentrations because of their high uncertainty in this study.

\section{Conclusions}

The modified model could predict the nitrobenzene time-dependent concentrations in various environmental compartments in the Songhua River and use them to identify the key processes that affected nitrobenzene concentration levels in the water media by a sensitivity analysis. The biomass changes for diatoms and mussel were significantly affected, whereas, no influence for other organisms could be predicted. The model presented here could be a useful tool to assess evolution trends rather than accurate values because of limited model input data and real environmental complexity. It needs to be modified further for real environmental characters, to obtain more reliable prediction results.

\section{Acknowledgements}

This work was supported by the National Natural Science Foundation of China (No. 20621703), the National Basic Research Program of China (No. 2007CB407301), and the Ministry of Science and Technology of China (No. 2006BA618A-01). The authors also thank the Songhua River Hydrological Station for supplying the detection data on nitrobenzene.

\section{References}

Ang M L, Peers K, Kersting E, Fassmann W, Tuomisto H, Lundström P, Helle M, Gustavsson V, Jacobsson P, 2001. The development and demonstration of integrated models for the evaluation of severe accident management strategiesSAMEM. Nuclear Engineering and Design, 209(1-3): 223-231.

Bartell S M, Lefebvre G, Kaminski G, Kaminski G, Carreau M, Campbell K R, 1999. An ecosystem model for assessing ecological risks in Que'bec rivers, lakes, and reservoirs. Ecological Modeling, 124: 43-67.

Bhatkhande D S, Pangarkar V G, Beenackers A A C M, 2003. Photocatalytic degradation of nitrobenzene using titanium dioxide and concentrationed solar radiation: chemical effects and scaleup. Water Research, 37: 1223-1230.

Chambers P A, Kalff J, 1985. Depth distribution and biomass of submersed aquatic macrophyte communities in relation to Secchi depth. Can J Fish Aquat Sci, 42: 701-709.

Chow T E, Gaines K F, Hodgson M E, Wilson M D, 2005. Habitat and exposure modelling for ecological risk assessment: A case study for the raccoon on the Savannah River Site.
Ecological Modelling, 189(1-2): 151-167.

Deneer J W, Sinnige T L, Seinen W, Hermens J L M, 1987. Quantitative structure-activity relationships for the toxicity and bioconcentration factor of nitrobenzene derivatives towards the guppy (Poecilia reticulata). Aquatic Toxicology, 10(23): $115-129$.

Geyer H, Politzki G, Freitag D, 1984. Prediction of ecotoxicological behaviour of chemicals: relationship between $n$-octanol/water partition coefficient and bioaccumulation of organic chemicals by alga Chlorella. Chemosphere, 13: 269-284.

Grimaldi J, Leduc G, 1973. The growth of the yellow perch in various Que'bec waters. Nat Can, 100: 165-176.

He M C, Sun Y, Li X R, Yang Z F, 2006. Distribution patterns of nitrobenzenes and polychlorinated biphenyls in water, suspended particulate matter and sediment from mid- and down-stream of the Yellow River (China). Chemosphere, 65(3): 365-374.

He M C, Wang Z J, Tang H X, 2001. Modeling the ecological impact of heavy metals on aquatic ecosystems: a framework for the development of an ecological model. The Science of Total Environment, 266: 291-298.

Jilin Province Hydrology Station, 1980, 1981, 1983. Hydrology Annual of the People's of Republic China. Vol 1. Changchun: Jilin Province Hydrology Station Press.

Kennedy J H, Johnson Z B, Wise P D, Johnson P C, 1995. Model aquatic ecosystems in ecotoxicological research: consideration of design, implementation, and analysis. In: Handbook of Ecotoxicology (Hoffman D. J., Rattner B. A., Burton Jr G. A., Cairns Jr J., eds.). Florida: CRC Press. 117162.

Kumblad L, Gilek M, Næslund B, Kautsky U, 2003. An ecosystem model of the environmental transport and fate of carbon-14 in a bay of the Baltic Sea, Sweden. Ecological Modelling, 166(3): 193-210.

Lacasse S, Magnan P, 1992. Biotic and abiotic determinants of the diet of brook trout, Salvelinus fontinalis, in lakes of Lauentian Shield. Can J Fish Aquat Sci, 49: 1001-1009.

Lang P Z, Yuan X, Ding Y Z, 1998. Reaction and Toxicity of Organic Pollutants in Songhua River. Changchun: Jilin Science and Technology Press. 2-200.

Larocque G R, Mauriello D A, Park R A, Rykiel Jr E J, 2006. Ecological models as decision tools in the 21st century: Proceedings of a conference organized by the International Society for Ecological Modelling (ISEM) in Que'bec, Canada, August 22-24, 2004. Ecological Modelling, 199(3): 217-218.

Naito W, Miyamoto K, Nakanishi J, Masunaga S, Bartell S M, 2002. Application of an ecosystem model for aquatic ecological risk assessment of chemicals for a Japanese lake. Water Research, 36: 1-14.

Naito W, Miyamoto K, Nakanishi J, Masunaga, S, Bartell S M, 2003. Evaluation of an ecosystem model in ecological risk assessment of chemicals. Chemosphere, 53: 363-375.

Park R A, Clough J S, Wellman M C, 2008. AQUATOX: modeling environmental fate and ecological effects in aquatic ecosystems. Ecological Modeling, 213(1): 1-15.

Patil S S, Shinde V M, 1988. Biodegradation studies of aniline and nitrobenzene in aniline plant wastewater by gas chromatography. Environ Sci Technol, 22: 1160-1165.

Pesticide Action Network, 2006. PAN Pesticides DatabaseChemical Toxicity Studies on Aquatic Organisms. http:// www.pesticideinfo.org/Search_Ecotoxicity.jsp \#Chemicals.

Ray S, Berec L, Straškraba M, Jørgensen S E, 2001. Optimization 
of exergy and implications of body sizes of phytoplankton and zooplankton in an aquatic ecosystem model. Ecological Modelling, 140(3): 219-234.

Ren M L, 1981. Fishes of the Amur River. Heilongjiang: Heilongjiang People's Publishing House.

Smith E P, Cairns Jr J, 1993. Extrapolation methods for setting ecological standards for water quality: Statistical and ecological concerns. Ecotoxicology, 2: 203-219.

Songliao Water Conservancy Committee, 1994. Songhua River Volume. Beijing: Water Power and Electric Power press.

Tang E P Y, Peters R H, 1995. The allometry of algal respiration. J Plankton Res, 17(2): 303-315.

USEPA (U.S. Environment Protection Agency), 1995. OPPT Chemical Fact Sheets: Nitrobenzene Fact Sheet. 749-F-95015a (7407).
USEPA (U.S. Environmental Protection Agency), 2004a. AQUATOX for Windows: A modular fate and effects model for aquatic ecosystems-Volume 1: User's Mannual. EPA-823R-04-001.

USEPA (U.S. Environmental Protection Agency), 2004b. AQUATOX for Windows: A modular fate and effects model for aquatic ecosystems-Volume 2: Technical Documentation. EPA-823-R-04-002.

USEPA (U.S. Environmental Protection Agency), 2004c. AQUATOX for Windows: A modular fate and effects model for aquatic ecosystems-Volume 3: Model Validation Reports. EPA-823-R-04-003.

USEPA (U.S. Environmental Protection Agency), 1996. Nitroaromatics and cyclic ketones by gas chromatography. http://www.accustandard.com/asi/pdfs/epa_methods/8091. 